\title{
ANALYSIS OF PRINCIPAL STRESS FACTORS AFFECTING DRIVERS IN DIFFERENT VEHICLES
}

Retta ZEWDIE, Department of Vehicles and Ground Transport, Faculty of Engineering, Czech University of Life Sciences, Kamýcká 129, 16500 Prague 6, Czech Republic, zewdie@tf.czu.cz (corresponding author)

Pavel KIC, Department of Technological Equipment of Buildings, Faculty of Engineering, Czech University of Life Sciences Prague, Kamýcká 129, 16500 Prague 6, Czech Republic, kic@tf.czu.cz

The aim of this research paper is to compare the effect of the heart rate variabilities on different vehicle drivers. The most common urban transport vehicles (bus, tram and metro) are compared with typical mobile agricultural machines (tractors and combine harvesters) and passenger car. The measurements were focused on the complexity and traffic routes, velocities of each vehicle and ages of drivers related to changes in the heart rate of drivers as main parameters. The authors characterize cardinal factors affecting the contentment of drivers while undertaking their performance. The results of the measurements showed that the lowest mean heart rate value was registered on metro (subway car) drivers scoring 59 bpm, whereas the bus drivers $80 \mathrm{bpm}$ and tram $77 \mathrm{bpm}$. The mean heart rate value of the combine harvester drivers scored $106 \mathrm{bpm}$ and tractor drivers $108 \mathrm{bpm}$, which indicates that the driver's heart rate of the agricultural machineries were significantly greater. The heart rate of tram drivers has increased significantly in a short period of time by $75 \%$, metro (subway) drivers by $59 \%$, combine harvester drivers by $23 \%$ and tractor drivers by $19 \%$, whereas the passenger car drivers' heart rate value increase was by $30 \%$. The driving velocity, drivers' age and weight showed its effect on the heart rate variabilities. The data collections were made by a heart rate measurement device. Relevant data on technical conditions stretch and shape design routes; as well as the heart rate variabilities on the respective drivers are collected carefully for detail statistical analysis.

Keywords: body weight, driver's age, heart rate variation, transport route

\section{INTRODUCTION}

Urban transport system complexity and other mobile technical machinery levels are associated with the improvement of technology. The way drivers perform their duties has an impact on stress effect which has an overall performance by the driver. Factors like driving on rough field (the case for agricultural machineries), traffic routes, and road intersection, up and down hill drives cause a considerable impact on overall situation leading to various stresses. Evaluated stress levels could be used to adapt the driver's environment to minimize distractions in high cognitive demanding situations and to promote stress-friendly driving behaviours. Lee, Chong, Teak (2017) studied an emotional responses categorizing in three classes: relaxed, stressed, and fatigued. In their result they proposed an application intelligent driver's safety alert system, to use those emotional responses to prevent accidents affecting themselves or other innocent victims. Munoz-Organero, Corcoba-Magana (2017) evaluated how effectively the upcoming stress levels can be predicted considering current stress levels, current driving behaviour, and the shape of the road, by using features, such as the positive kinetic energy and severity of curves on the road to estimate how stress levels will evolve. Varela-Mato, et. al (2017) Considered unhealthy lifestyle behaviours such as a lack of physical activity and high levels of sedentary behaviour (sitting) likely to contribute to this elevated risk. In the conclusion, the authors highlighted that drivers demonstrate a high-risk cardio-metabolic profile and are highly sedentary and physically inactive. Interventions were recommended in educational programmes to raise awareness about diet and exercise. Prolonged driving on monotonous roads often leads to a reduction in task load that causes drivers passive fatigue. Passive fatigue results in loss of driver alertness and is detrimental to driver safety.

This paper focuses on the effect of a haptic guidance steering system on improving behaviours of passively fatigued drivers. Research results (Wang, et al, 2017) on of physiological measures, including heart rate variability and percentage of eye closure. In conclusion, the activation of haptic guidance can be regarded as an effective countermeasure for the passively fatigued drivers who have performed a prolonged monotonous driving task. Passively fatigued drivers were aroused when they were aware of the active torque on the steering wheel. Zewdie, Kic (2016), pointed out that the influence of transport route segments characteristics and other complications have impacts on the heart rate variabilities. Zhang, et. al. (2017) showed in their research that heart rate is obtained by capturing the colour variations resulting from blood circulation in facial skin. Compared with existing commercial detection equipment, the non-contact detection method can conveniently measure the heart rate with acceptable accuracy, especially during driving situations that require extra precaution. The authors of this research paper have come to conclusions that the impact of the heart rate variability could be caused by the comfort in driving cabins, route segments, driving velocity, age and weights of individual drivers. 


\section{MATERIALS AND METHODS}

The authors performed the research on three categories of vehicles. The most common urban transport vehicles (bus, tram and metro), which are commonly used in Prague city urban public transport system are compared with typical mobile agricultural machineries like tractors and combine harvesters. Czech brand buses Karosa KbN B941 City Buses $(n=5)$, the Czech brand trams T3 (n=3) and the Russian brand M1 modified metro $(n=4)$ on which the research was performed. The buses, trams and metro drivers' heart rate were measured in mild hot summer time of July and August 2015. The time and route was selected so that every driver had very similar weather and driving conditions. The measurements were taken on the same route, two round trips by each driver. For additional verification, in September 2017, the authors have measured a passenger car VW Passat Variant $(n=3)$ driver heart rate in three driving lines (city, motorway and first category roads). Similarly, the agricultural machineries such as tractors $(\mathrm{n}=3)$ and combine harvesters $(n=3)$ were part of the research findings. The authors compared the drivers' heart rate variabilities in relation to driving velocity, their age and weight. All participants of the research were volunteers with the Prague transport management for two summers (relatively mild climates - July 2015 and August 2016). Data was collected on each individual driver. Although the research was confidential, we took into consideration the background of each and every individual driver. The specific information on all twenty-three drivers and six categories of vehicles are summarized on Table 1.

Agricultural machinery operators are exposed to unfavourable weather conditions which lead to health problems. Beside extreme cold winter and heat in summer, operators often encounter a heavy and predominant workload during the summer harvest time. Due consideration is not given enough to this problem. This research finding specifies the stress caused by the fatigue related to the actual workload on farm fields, which is a ride over rough agricultural terrain and short-distance run transport. This paper presents the outcome of the stress factors affecting observed operations carried out by two different types of farm machinery operators, tractor and combine harvester, in their respective working processes. Data on operators' heart rate variation throughout the course of harvest and transport performance is carefully collected. The impacts of farm field segments, operators' manipulations as well as obstacles occurred while performing the harvest, transporting machines is the core of this research often presumed the cause changes of heart rate.

For the actual measurement, the driver should put on a sensor (Polar RS800CX) around the body and computer device on the wrist of the driver to record the heart rate variability (HRV). The package of the measurement instrument consists of four parts brand of Polar. The Polar RS800CX is a computer which displays and records the heart rate and other data like position and velocity during driving examination; Polar wear link W. I. N. D. a transmitter, sends the heart rate signal to the computer. It includes connector and strap; CD-ROM which includes software and a complete user manual for the RS800CX computer. Relevant data was collected from measurement devices which are installed on the body and wrist of the performing driver. Data detected (heart rate of the driver, position and velocities of the vehicles) are stored in Polar RS800CX transformed through infraport to a personal computer for further processing and analysis. All data were measured continuously and stored at intervals of one minute to the measuring instrument ALMEMO 26908 during the measurement.

The data on drivers' heart rate variation (HRV) from all twenty one driving lines are carefully collected for further analysis. The obtained results were processed by Excel software and verified by statistical software (Tukey HSD Test). Different superscript letters ( $a, b, c, d, e$ and f) mean values in common are significantly different from each other in the rows of the (ANOVA; Tukey HSD Test; $p \leq 0,05$ ), e.g. if there are the same superscript letters in all the rows it means the difference between the values are not statistically significant at the significance level of 0,05 .

\section{RESULTS AND DISCUSSION}

The mean and maximum values including standard deviation were calculated from the results of measurements each driver's heart rate variabilities parameter for all 23 drivers and 6 vehicles are shown on Table 2. From the results of the measurement the highest mean was observed on tractor drivers $108 \mathrm{bpm}$, followed by combine harvester drivers 106 bpm; whereas the least mean heart rate was observed on metro (subway car) drivers i.e. $59 \mathrm{bpm}$, followed by tram drivers $77 \mathrm{bpm}$. On the other hand the maximum heart rate was observed on Metro (subway car) drivers 135 bpm followed by the combine harvester drivers i.e. $130 \mathrm{bpm}$. The highest heart rate increase $(75 \%)$ was registered on tram drivers, followed by metro (subway car) drivers (59\%). From the result, it is clearly seen that the drivers of rail vehicles has an impact on the stress issue caused by sliding rails (for both metro and tram) and traffic jams (for trams) on crossroads during peak hours. The authors' only suspect that the metro (subway) high increase in heart rate has occurred from low visibility in the tube and light variation.

Table 1 . The summery of the drivers average Heart rate

\begin{tabular}{|c|c|c|c|c|c|c|c|}
\hline \multicolumn{2}{|c|}{ Vehicle type } & Bus & Metro & Tram & Tractor & Combine Harvester & Passenger Car \\
\hline \hline Number of drivers & - & 5 & 4 & 3 & 3 & 3 & 3 \\
\hline Age & year & 39 & 46 & 55 & 48 & 39 & 61 \\
\hline Weight & $\mathrm{kg}$ & 95 & 78 & 90 & 92 & 109 & 84 \\
\hline
\end{tabular}


Table 2 indicates the six vehicles drivers' heart rate variation. The standard deviations on Mean HR, Maximum $\mathrm{HR}$ and the increase in heart rates with different indexes show the statistical significances. Different superscript letters (a, $\mathrm{b}, \mathrm{c}, \mathrm{d}, \mathrm{e}$, and $\mathrm{f}$ ) mean values in common are significantly different from each other in the column (ANOVA; Tukey HSD Test; $p \leq 0.05)$.

Table 2. Statistical importance among drivers heart rate variability

\begin{tabular}{|c|c|c|c|}
\hline Vehicle & Mean HR $[\mathrm{bpm} \pm$ SD] & Max HR[bpm \pm SD $]$ & Increase HR[\% \pm SD ] \\
\hline \hline Bus & $80 \pm 4,21^{\mathrm{a}, \mathrm{b}, \mathrm{c}, \mathrm{e}, \mathrm{f}}$ & $108 \pm 4,21^{\mathrm{a}, \mathrm{b}, \mathrm{c}, \mathrm{e}, \mathrm{d}, \mathrm{f}}$ & $135 \pm 4,21^{\mathrm{a}}$ \\
\hline Metro & $59 \pm 7,06^{\mathrm{a}, \mathrm{b}, \mathrm{c}}$ & $94 \pm 7,06^{\mathrm{a}, \mathrm{b}, \mathrm{c}, \mathrm{f}}$ & $159 \pm 7,06^{\mathrm{a}}$ \\
\hline Tram & $77 \pm 7,01^{\mathrm{a}, \mathrm{b}, \mathrm{c}, \mathrm{e}, \mathrm{f}}$ & $135 \pm 7,01^{\mathrm{a}, \mathrm{b}, \mathrm{c}, \mathrm{d}, \mathrm{e}}$ & $17 \pm 7,01^{\mathrm{a}}$ \\
\hline Tractor & $108 \pm 4,57^{\mathrm{d}, \mathrm{e}, \mathrm{f}}$ & $129 \pm 4,57^{\mathrm{a}, \mathrm{c}, \mathrm{d}, \mathrm{e}, \mathrm{f}}$ & $119 \pm 4,57^{\mathrm{a}}$ \\
\hline Combine Harvester & $106 \pm 6,91^{\mathrm{d}, \mathrm{e}, \mathrm{f}}$ & $130 \pm 6,91^{\mathrm{a}, \mathrm{c}, \mathrm{d}, \mathrm{e}, \mathrm{f}}$ & $123 \pm 6,91^{\mathrm{a}}$ \\
\hline Passenger Car & $98 \pm 5,31^{\mathrm{a}, \mathrm{c}, \mathrm{d}, \mathrm{e}, \mathrm{f}}$ & $127 \pm 5,31^{\mathrm{a}, \mathrm{b}, \mathrm{c}, \mathrm{d}, \mathrm{e}, \mathrm{f}}$ & $130 \pm 5,31^{\mathrm{a}}$ \\
\hline
\end{tabular}

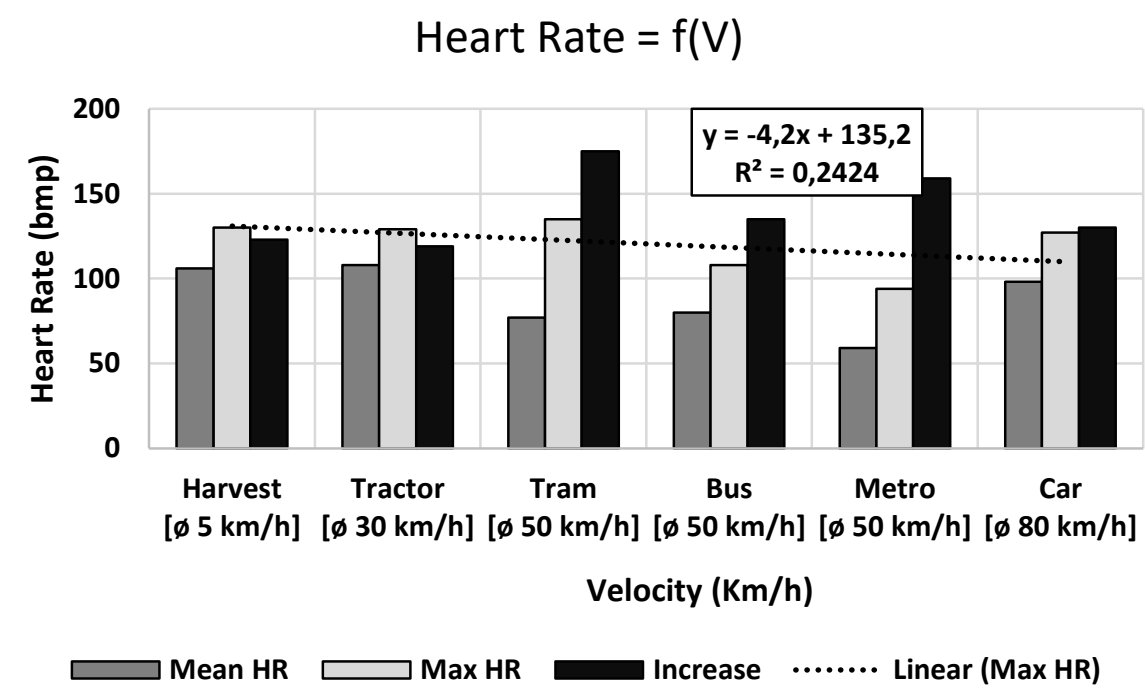

Figure 1. The relation between driver's heart rate and average velocities of vehicles

The graph on Fig. 1 shows heart rate variability related to the average operational velocity of each group of vehicle. From the graph, it is seen that the decreasing trend of the heart rate with the increase of velocity.

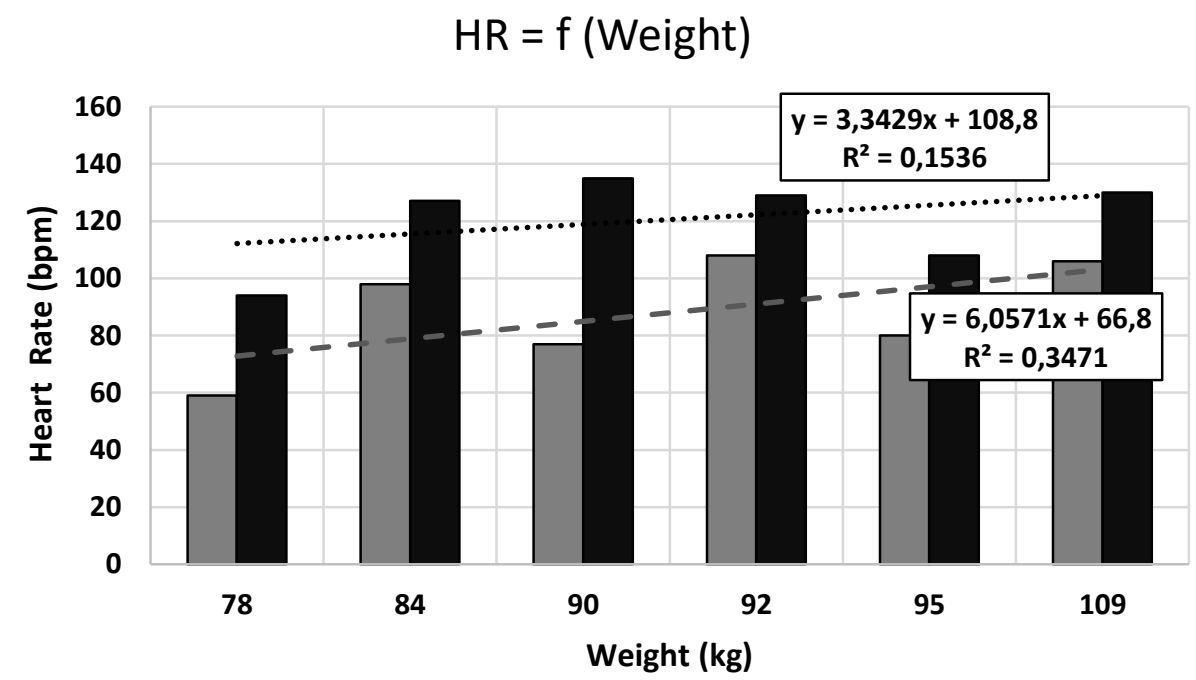

$\square$ Mean HR Max HR - - - Linear (Mean HR)

Linear (Max HR)

Figure 2. The relation between drivers' heart rate and average weights

Graph on Fig. 2 demonstrates weight of drivers' contribution to the rise of heart rates. From the data and graph, it is seen that the more the weight of the driver, the increase of the heart rate. 


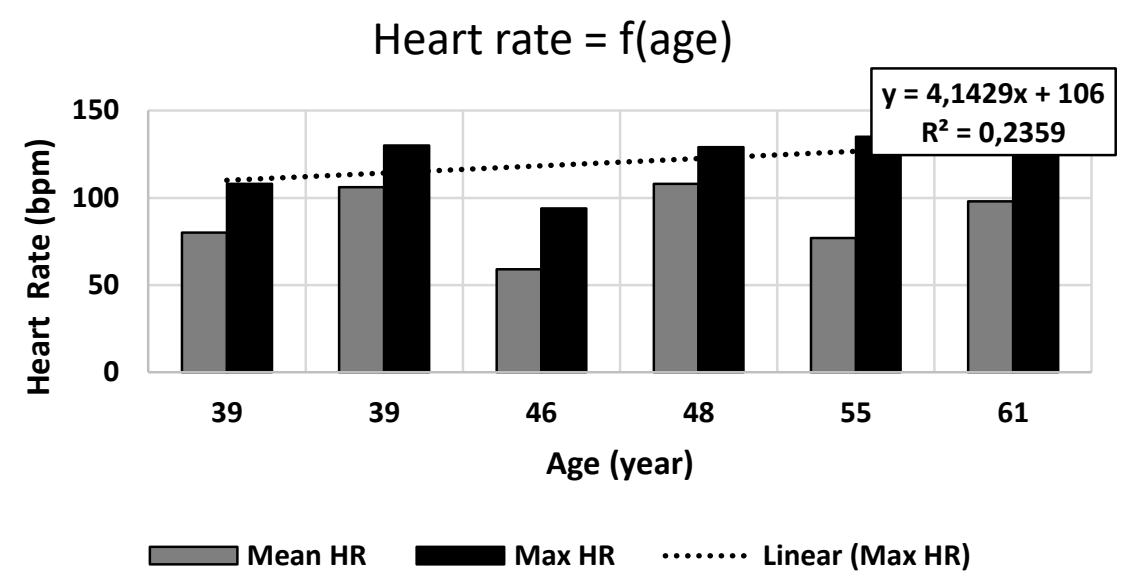

Figure 3. The relation between driver's heart rate and average age

The increasing trend of heart rate on graph shown on Fig. 3 corresponds with the increase of ages. The graph demonstrates both mean HR and max HR as increasing.

\section{CONCLUSION}

The mean heart rate of tram drivers $77 \mathrm{~min}^{-1}$ demonstrates that it exceeded significantly to the maximum heart rate $135 \mathrm{bpm}$ with the increase of $175 \%$. In the case of metro (subway car) trends replicates the characteristics of the tram where the mean heart rate $59 \mathrm{bpm}$ exceeded to the maximum heart rate $94 \mathrm{bpm}$ with the increase of $159 \%$. From the Table 2 , the authors came to a conclusion that the rail vehicle drivers have the highest heart rate variabilities compared to the other drivers' heart rate. From the result, it is clearly seen that stress issue of the drivers of rail vehicles is caused by sliding rails (for both metro and tram) and traffic jams (for trams) on crossroads during peak hours. The authors' only suspect that the heart rate of metro (subway car) drivers is increased in due to low visibility in the tube and sudden light variation.

High increases of heart rate were observed on bus drivers (135\%) and passenger car drivers (130\%). Bus drivers' heart rate variabilities are influenced significantly by features of route segments causing variable stress. The passenger car drivers also exhibited changes in heart rate variabilities depending on the course of the route.

The increase in heart rate has been observed on both agricultural machinery drivers, which are relatively lower (tractor driver $119 \%$ and combine harvester driver 123\%).

Average operational speed of each vehicle has influence on maximum heart rate variation (Fig. 1). From the graph, it is clearly seen that with the increasing velocity the minimum heart rate has a decreasing trend. In similar case the average age of driver has impact on heart rate variation. The data collected on the average weight of each driving group have impacts on increasing mean heat rate and increasing maximum heart rates as indicated on Fig. 2. The graph (Fig. 3) indicates the increasing values of ages on the increasing heart rate.

The paper contributes the information on the relationships between different measured working parameters affecting the heartbeats of different drivers. The authors are well aware of the number of participants to be inadequate (twenty three different drivers). They social backgrounds, health problems, years of driving experiences, etc. which are not considered for this research are among the valuable data for better evaluation. Extensive research should be conducted on much more drivers for better results.

\section{REFERENCES}

1. Lee, Boon Giin; Chong, Teak Wei; Lee, Boon Leng; et al. 2017. Wearable Mobile-Based Emotional Response-Monitoring System for Drivers. IEEE Transactions nn Human-Machine Systems, Vol. 47, Iss. 5, pp. 636-649. https://doi.org/10.1109/TITS.2016.2618424

2. Munoz-Organero, Mario; Corcoba-Magana, Victor. 2017. Predicting Upcoming Values of Stress While Driving. IEEE Transactions on Intelligent Transportation Systems, Vol. 18, Iss.7, pp. 1802-1811. https://doi.org/10.1136/bmjopen-2016-013162

3. Varela-Mato, Veronica; O'Shea, Orlagh; King, James A.; et al. 2017. Cross-sectional surveillance study to phenotype lorry drivers' sedentary behaviours, physical activity and cardio-metabolic health. BMJ Open, Vol. 7, Iss. 6, Article No. e013162.

4. Wang, Z., Zheng, R., Kaizuka, T., Keisuke S., Kimihiko, N. 2017. The Effect of a Haptic Guidance Steering System on FatigueRelated Driver Behaviour. IEEE Transactions on Human Machine Systems, Vol. 47, Iss. 5, pp. $741-748$. https://doi.org/10.1109/THMS.2017.2693230

5. Zewdie, R., Kic, P. 2016. Transport Route segments and stress effect on drivers. Proceedings of international conference Agronomy Research, , Vol. 14, No 1, pp. 269-279.

6. Zhang, Q., Wu, Q., Zhou, Y., Xinyu, W., Yongsheng, O., Huazhang Z. 2017. Webcam-based, non-contact, real-time measurement for the physiological parameters of drivers. Measurement, Vol. 100, pp. 311-321. https://doi.org/10.1016/j.measurement.2017.01.007 